\title{
Photocatalytic Water Splitting with Suspended Calcium Niobium Oxides: Why Nanoscale is Better than Bulk - A Kinetic Analysis
}

\author{
Erwin M. Sabio, ${ }^{\dagger}$ Rachel L. Chamousis, $^{\dagger}$ Nigel D. Browning, ${ }^{\ddagger}$ and Frank E. Osterloh ${ }^{*}{ }^{\dagger}$ \\ ${ }^{\dagger}$ Department of Chemistry and Department of Chemical Engineering and Materials Science and Department of Molecular and \\ Cellular Biology, University of California, Davis, One Shields Avenue, Davis, California 95616, United States
}

\section{Supporting Information}

\begin{abstract}
The layered Dion-Jacobson phase $\mathrm{KCa}_{2} \mathrm{Nb}_{3} \mathrm{O}_{10}$ is known to catalyze photochemical water reduction and oxidation under UV light in the presence of sacrificial agents. The same reactions are catalyzed by tetrabutylammonium hydroxide-supported $\mathrm{HCa}_{2} \mathrm{Nb}_{3} \mathrm{O}_{10}$ nanosheets obtained by chemical exfoliation of the parent phase. Here we describe a factorial study into the effects of nanoscaling, sacrificial charge donors, cocatalysts, and cocatalyst deposition conditions on the activity of these catalysts. In water, nanoscaling leads to a 16-fold increase in $\mathrm{H}_{2}$ evolution and an 8-fold increase in $\mathrm{O}_{2}$ evolution over the bulk phase under the same conditions. The sacrificial electron donor methanol improves $\mathrm{H}_{2}$ production by 2-3 orders of magnitude to $20-30 \mathrm{mmol}$ of $\mathrm{H}_{2} / \mathrm{h} / \mathrm{g}$, while the electron acceptor $\mathrm{AgNO}_{3}$ increases $\mathrm{O}_{2}$ production to $400 \mu \mathrm{mol}$ of $\mathrm{O}_{2} / \mathrm{h} / \mathrm{g}$. Rates for $\mathrm{H}_{2}$ and $\mathrm{O}_{2}$ evolution further depend on the presence of cocatalysts ( $\mathrm{Pt}$ or $\mathrm{IrO}_{x}$ ) and, in the case of $\mathrm{H}_{2}$, inversely on their

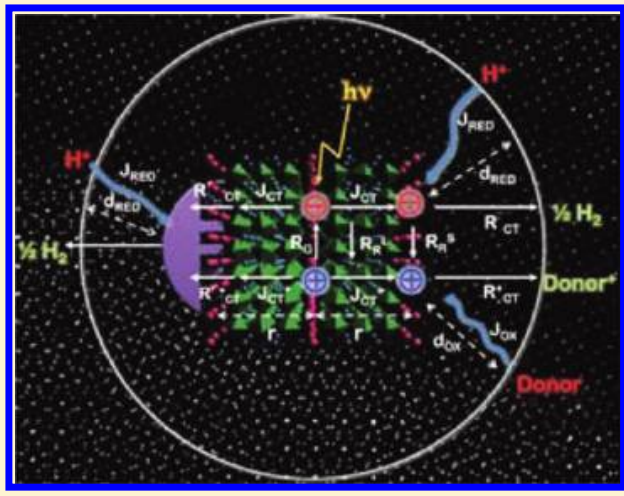
particle size. To rationalize these findings and the increased activity of the nanoscale particles, we propose a kinetic model for photocatalysis with semiconductor particles. The model calculates the electronic rate of the catalysts as a product of terms for charge generation, charge and mass transport, chemical conversion, and charge recombination. The analysis shows that the activity of the catalysts is limited mainly by the kinetics of the redox reactions and by the rate of charge transport to the water-catalyst interface. Mass transport in the solution phase does not play a major role, and neither does surface charge recombination.
\end{abstract}

\section{INTRODUCTION}

Photocatalytic water splitting is considered a promising source for clean hydrogen fuel from abundant sunlight. ${ }^{1-5}$ Several transition metal oxides have been shown to catalyze the water splitting reaction or part of it, usually in the presence of a metal or metal oxide cocatalyst and sometimes with sacrificial agents in solution. ${ }^{6-11}$ Recent work has suggested that nanoscaling leads to improved catalytic properties over the bulk forms because it increases the specific surface area and shortens pathways for electron and hole transport. Improved photochemical properties have been demonstrated for $\mathrm{Fe}_{2} \mathrm{O}_{3}$ nanocrystalline films or particles, $9,12,13$ and unusual photocatalytic water oxidation activity has been found for $\mathrm{IrO}_{2}$ nanocrystals, despite its metallic character. ${ }^{14}$ To further investigate the effect of nanoscaling on the photocatalytic properties of inorganic semiconductors, we perform here a systematic comparison between Dion-Jacobsen phase $\mathrm{KCa}_{2} \mathrm{Nb}_{3} \mathrm{O}_{10}$ and crystalline nanosheets derived from it by exfoliation with tetrabutylammonium (TBA) hydroxide (Figure 1). ${ }^{7,15-17}$

Both the nano- and the bulk niobate contain the $\mathrm{Ca}_{2} \mathrm{Nb}_{3} \mathrm{O}_{10}{ }^{-}$ structure motif. In the case of the bulk niobate, the $\mathrm{Ca}_{2} \mathrm{Nb}_{3} \mathrm{O}_{10}{ }^{-}$ layers are stacked with alternating layers of potassium ions, whereas for the nanoniobate, individual tetrabutylammonium supported $\mathrm{Ca}_{2} \mathrm{Nb}_{3} \mathrm{O}_{10}{ }^{-}$layers are present in solution. Under
UV irradiation, both niobates are able to photocatalytically reduce water into hydrogen with the aid of methanol ${ }^{18-21}$ and, as we show here, photooxidize water with the aid of silver nitrate. Over 30 irradiation experiments were employed to show that the activity of each catalyst is strongly dependent on the presence of sacrificial agents, cocatalysts, and their size. We find that the activity of the nanoniobate exceeds the corresponding bulk catalysts by over an order of magnitude. To understand this difference, we perform a kinetic analysis of the photocatalytic process. Here the performance of each catalyst is analyzed in terms of rates for charge generation, charge transport, electrochemical conversion, mass transport, and lattice and surface recombination. The analysis reveals that the higher activity of the nanoscale catalysts is mainly due to improved charge transport to the catalyst surface and that the activity of both catalysts is limited by the kinetics of water electrolysis. Surface recombination does not appear to limit the hydrogen evolution activity of the nanoniobate, and neither does mass transport in the solution phase.

Received: September 17, 2011

Revised: December 20, 2011

Published: January 25, 2012 


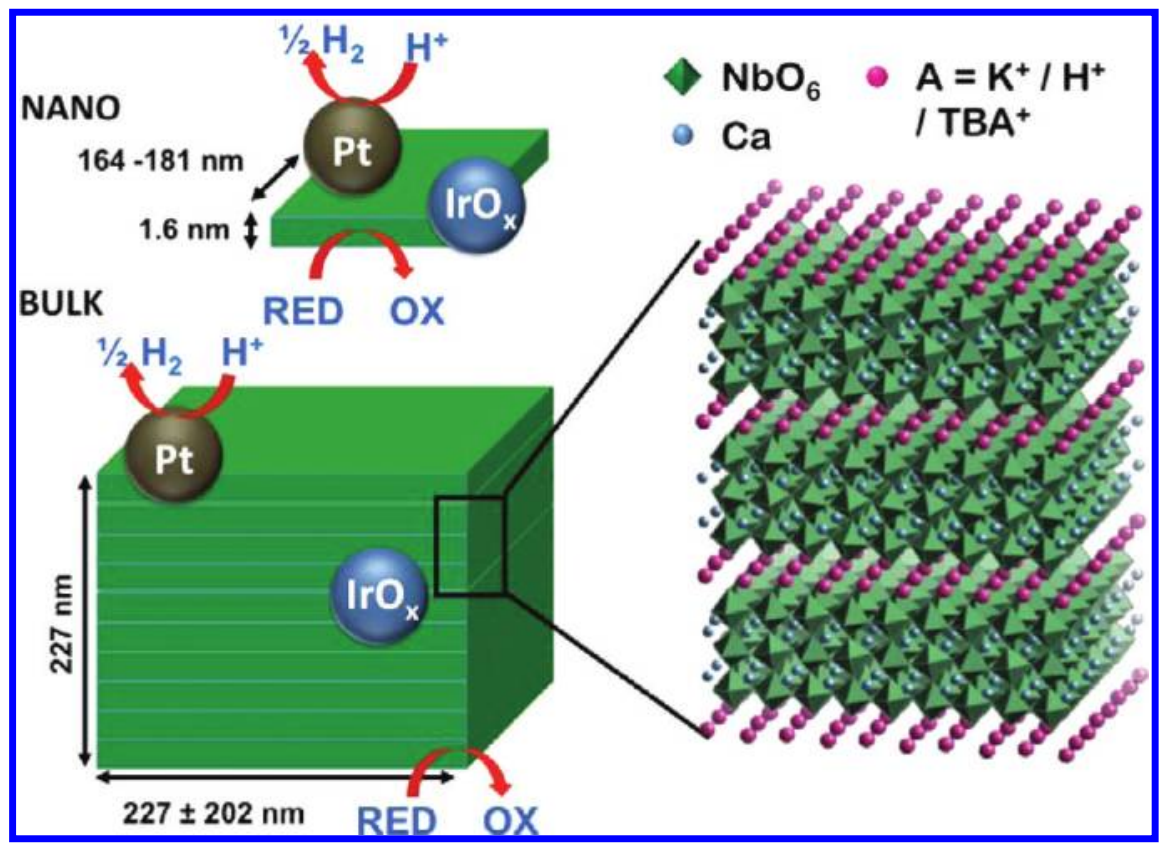

Figure 1. Bulk niobate $\mathrm{KCa}_{2} \mathrm{Nb}_{3} \mathrm{O}_{10}$ consists of sheets of corner-shared $\mathrm{NbO}_{6}$ octahedra with intercalated $\mathrm{Ca}^{2+}$ ions that are held together by layers of $\mathrm{K}^{+}$ions. Exfoliation with $\mathrm{TBA}^{+}$(tetrabutylammonium) produces the nanoniobate as individual nanosheets. Both niobates are functionalized with photodeposited $\mathrm{Pt}$ or $\mathrm{IrO}_{x}$ nanoparticles to serve as active sites for $\mathrm{H}_{2}$ and $\mathrm{O}_{2}$ production, respectively.

\section{EXPERIMENTAL SECTION}

Reagents. $\mathrm{K}_{2} \mathrm{CO}_{3}, \mathrm{CaCO}_{3}, \mathrm{Nb}_{2} \mathrm{O}_{5}$, and tetrabutylammonium hydroxide, $\mathrm{TBA}(\mathrm{OH})\left(40\right.$ wt $\%$ in $\mathrm{H}_{2} \mathrm{O}$ ), were purchased from Acros Organics, Morris Plains, NJ. $\mathrm{H}_{2} \mathrm{PtCl}_{6} \cdot 6 \mathrm{H}_{2} \mathrm{O}, \mathrm{K}_{3} \mathrm{IrCl}_{6}$, and $\mathrm{HNO}_{3}(70 \%)$ were purchased from Sigma-Aldrich, Milwaukee, WI. $\mathrm{KNO}_{3}$ and $\mathrm{AgNO}_{3}$ were obtained from Fisher Scientific, Pittsburgh, PA. Reagents were of reagent quality and used as received. Water used was purified to $>18 \mathrm{M} \Omega \cdot \mathrm{cm}$ resistivity using a Nanopure II system.

Catalyst Preparation. $\mathrm{KCa}_{2} \mathrm{Nb}_{3} \mathrm{O}_{10}$ and $\mathrm{TBACa}_{2} \mathrm{Nb}_{3} \mathrm{O}_{10}$ were synthesized according to published procedures. ${ }^{15,16}$ To prepare variants of $\mathrm{TBACa}_{2} \mathrm{Nb}_{3} \mathrm{O}_{10}$, three sets of five colloidal suspension aliquots containing $100 \mathrm{mg}$ of nanosheets as determined by gravimetric analysis were washed three times followed by centrifugation to remove excess TBA and to bring the $\mathrm{pH}$ down to $7-8$. The aliquots in each set were treated as follows: The first aliquot is dissolved in $100 \mathrm{~mL}$ of water. To another aliquot, $5.3 \mathrm{mg}$ of $\mathrm{H}_{2} \mathrm{PtCl}_{6} \cdot 6 \mathrm{H}_{2} \mathrm{O}$ corresponding to 2 wt \% $\mathrm{Pt}$ was added and then diluted to $100 \mathrm{~mL}$ with water. ${ }^{22}$ To a third aliquot, the same amount of hexachloroplatinic acid and $20 \mathrm{~mL}$ of $\mathrm{MeOH}$ were added and then topped off to $100 \mathrm{~mL}$ with water. A fourth $100 \mathrm{~mL}$ mixture was prepared by mixing 100 $\mathrm{mg}$ of the nanosheets and $4.7 \mathrm{mg}$ of $\mathrm{K}_{3} \mathrm{IrCl}_{6}\left(2 \mathrm{wt} \% \mathrm{IrO}_{x}\right.$ ) in water. A fifth suspension with the same mass of $\mathrm{K}_{3} \mathrm{IrCl}_{6}$ in 100 $\mathrm{mL}$ of $5 \mathrm{mM}$ aqueous $\mathrm{KNO}_{3}$ was similarly made. ${ }^{23}$ Aliquots in the other two sets are treated the same way. Each mixture was transferred one at a time to a $100 \mathrm{~mL}$ quartz flask and was degassed through three evacuation/Ar purge cycles. The mixture was then stirred at $600 \mathrm{rpm}$ and irradiated at $~ 550$ Torr for $1 \mathrm{~h}$ using a $300 \mathrm{~W}$ Cermax PE300BUV Xe lamp. Solid products were collected via centrifugation on a Fisher Scientific Marathon 2100 centrifuge at $13750 \mathrm{rpm}$. The samples were subsequently washed six times with $\mathrm{H}_{2} \mathrm{O}$ and then dried for $8 \mathrm{~h}$ under vacuum at $45{ }^{\circ} \mathrm{C}$. The dried samples were weighed and stored in the dark until use. Variants of $\mathrm{KCa}_{2} \mathrm{Nb}_{3} \mathrm{O}_{10}$ were prepared using the procedures described above.
$\mathrm{H}_{2}$ and $\mathrm{O}_{2}$ Evolution Experiments. Dried samples weighing 25-100 mg were ground and briefly sonicated until welldispersed in $100 \mathrm{~mL}$ of $\mathrm{H}_{2} \mathrm{O}, 20$ vol \% aqueous $\mathrm{MeOH}$, or $40 \mathrm{mM}$ aqueous $\mathrm{AgNO}_{3}$, with a final $\mathrm{pH}$ of $8-10$. The dispersions were transferred one at a time to a quartz flask and then evacuated/backfilled with Ar five times to a final pressure of 550 Torr. The mixture was stirred at $600 \mathrm{rpm}$ and irradiated over $5 \mathrm{~h}$ with a $300 \mathrm{~W}$ Cermax PE300BUV Xe lamp. The measured temperature in the flask was $30{ }^{\circ} \mathrm{C}$. Gas from the flask was sampled at the start of irradiation and in subsequent hours and then injected into a Varian 3800 gas chromatograph (GC) with Ar as carrier gas, a 60/80 Å molecular sieve column, and a thermal conductivity detector. Irradiated samples were collected via centrifugation, washed six times with $\mathrm{H}_{2} \mathrm{O}$, and stored in $15 \mathrm{~mL}$ of $\mathrm{H}_{2} \mathrm{O}$ for future analysis. Light intensity measurements were carried out using an IL1400A Photometer with a SED(SEL)365 Gallium Nitride Detector from International Light Technologies. The irradiation power was $26.33 \mathrm{~mW} / \mathrm{cm}^{2}$ at $250-380 \mathrm{~nm}$.

Microscopy. High-angle annular dark field STEM (HAADF-STEM) images were collected with a spherical aberration-corrected JEOL $2100 \mathrm{~F}$ with an accelerating voltage of $200 \mathrm{kV}$. Images were taken at $8 \mathrm{~cm}$ camera length. Electron microscopy samples were mounted onto a 400-mesh $\mathrm{Cu}$ grid with lacey carbon film.

Electrochemical Measurements. Electrochemical measurements were performed using a three-electrode cell equipped with a Pt counter electrode and SCE reference electrode. A gold electrode $\left(1.0 \mathrm{~cm}^{2}\right.$ exposed area) covered by the niobate samples served as the working electrode. Films of the niobates were fabricated by drop-coating the aqueous suspensions and drying in air. The electrolyte (aqueous $0.1 \mathrm{M} \mathrm{K}_{2} \mathrm{SO}_{4}$ at $\mathrm{pH} 7$ with $10 \% \mathrm{v}: \mathrm{v}$ methanol) was degassed with nitrogen for ten minutes prior to each measurement. The potential of the $\mathrm{K}_{4}\left[\mathrm{Fe}(\mathrm{CN})_{6}\right]$ redox couple $(+0.36 \mathrm{~V}$ vs $\mathrm{NHE})$ was used to calibrate the system. Potentials were generated and currents observed with a Gamry Reference 600 potentiostat controlled 


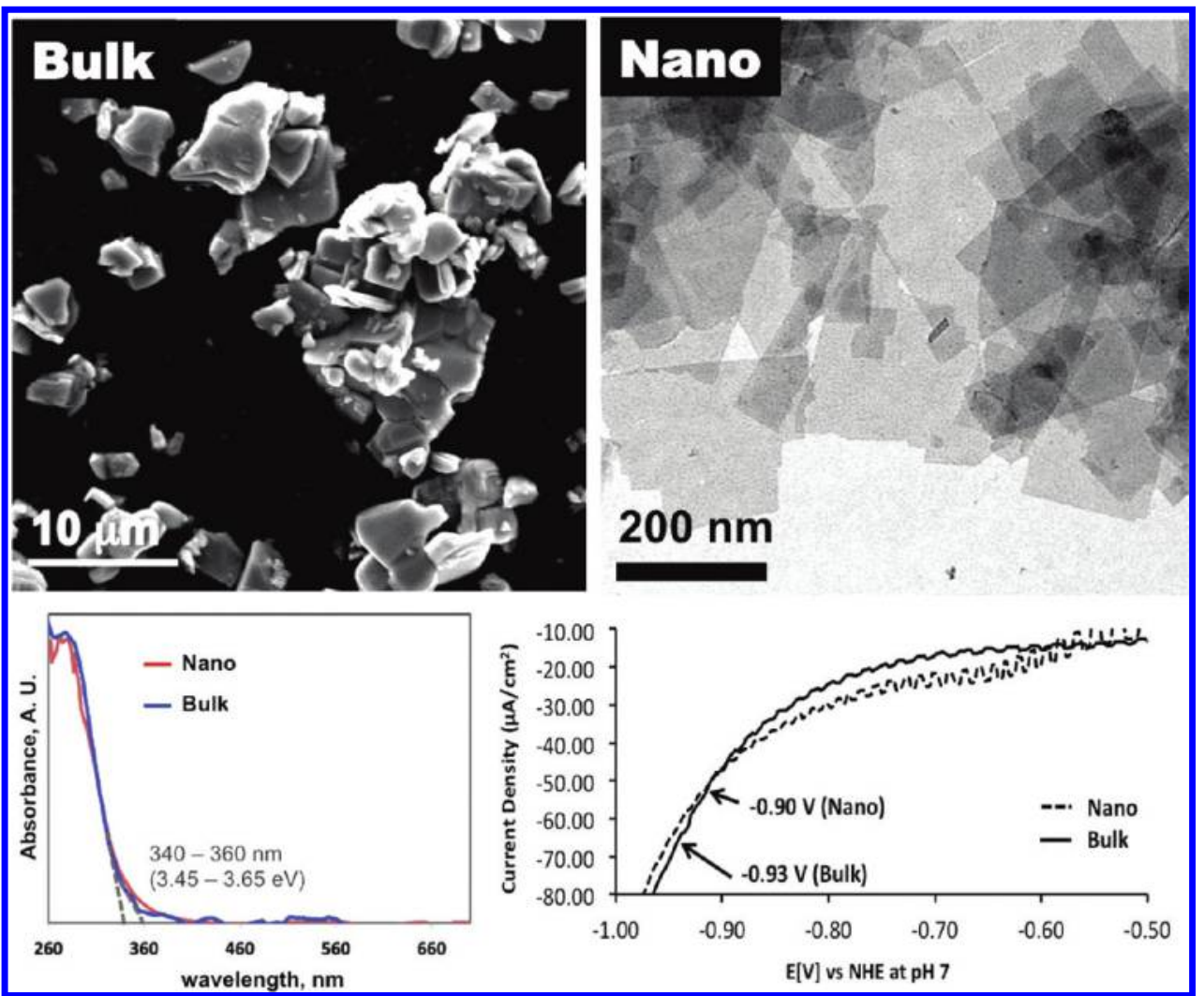

Figure 2. SEM and TEM micrographs of bulk and nanoniobate. Bottom left: Diffuse reflectance UV/vis spectra on thin films of the niobates. Bottom right: Photoelectrochemical onset scans on niobate films (on gold) in aqueous $0.1 \mathrm{M} \mathrm{K}_{2} \mathrm{SO}_{4}$ at pH 7 with $10 \%$ v:v methanol, under chopped light. Potentials are reported versus the normal hydrogen electrode.

by a PC. Photocurrent onset potentials were determined by applying cathodic scans $(10 \mathrm{mV} / \mathrm{s})$ under chopped light. Illumination was provided by a $300 \mathrm{~W}$ Xe arc lamp, equipped with a water filter, using a $\mathrm{SiO}_{2}$ fiber optics cable that delivered $100 \pm 20 \mathrm{~mW} / \mathrm{cm}^{2}$ at the electrode, as measured with a $\mathrm{GaN}$ photodetector.

Diffuse Reflectance UV-vis Spectra. Spectra were collected using an Ocean Optics DH2000 light source and HR2000 CG-UV-NIR spectrometer.

\section{RESULTS AND DISCUSSION}

Electron microscopy images of bulk and nanoscale niobates are shown in Figure 2 (additional HAADF STEM images are shown in Figures S-1 and S-2, Supporting Information). The bulk particles appear as randomly shaped blocks of mean thickness of $227 \pm 202 \mathrm{~nm}$. In contrast, the nanoniobate particles form thin sheets with $164 \times 181 \times 1.1 \mathrm{~nm}$ average dimensions. Because the $\mathrm{Ca}_{2} \mathrm{Nb}_{3} \mathrm{O}_{10}$ structure motif is preserved in both compounds, no significant alteration of the physical properties is expected in going from the bulk to the nanoscale. Indeed, UV/vis spectra and photoelectrochemical data (Figure 2) confirm that both compounds have a bandgap of $3.45-3.65 \mathrm{eV}$ and a flatband potential between -0.90 and $-0.93 \mathrm{~V}$ at $\mathrm{pH}=7$, versus NHE (based on photoelectrochemical onset potentials).

To probe the effect of cocatalysts on the photocatalytic properties, nano- and bulk niobates were modified by photoelectrodeposition of platinum and iridium dioxide nanoparticles, under variable conditions (in the presence and absence of the electron donor methanol or the electron acceptor $\mathrm{KNO}_{3}$ ). The morphologies of the resulting samples are shown in Figure 3.
When $\mathrm{Pt}$ is photodeposited in water without methanol, particles are very small (mean diameter $=0.82 \pm 0.21 \mathrm{~nm}$ ) and are attached to the surface with a particle density of $0.172 \pm$ $0.031 \mathrm{~nm}^{-2}$. With $\mathrm{MeOH}$, particles are larger and crystalline with mean diameters of $2.9 \pm 0.9 \mathrm{~nm}$ but are found sparsely on edges or trapped between sheets. We have previously attributed the larger particle $\mathrm{Pt}$ size to methanol-induced homogeneous nucleation. ${ }^{21}$ Platinum particles grown on the bulk niobate are larger $(3.1 \pm 8.1 \mathrm{~nm}$ mean diameter $)$ than on the nanomaterial. This is likely due to the smaller number of active sites, which promotes growth over nucleation. For particles grown without $\mathrm{MeOH}$, the size distribution is bimodal with small particles $(<1 \mathrm{~nm}$ in diameter) found densely covering the surface and large aggregates $(10-20 \mathrm{~nm}$ in diameter) on the edges. The mean particle density is $0.155 \pm 0.045 \mathrm{~nm}^{-2}$. For Pt photodeposited with $\mathrm{MeOH}$, the size distribution is similar, but the spatial distribution is spottier with more particles located on edges. Clearly for $\mathrm{Pt}$, the main effect of $\mathrm{MeOH}$ during photodeposition is a significant decrease in deposition density. In contrast to platinum, $\mathrm{IrO}_{x}$ particles photodeposited onto the nanoniobate are very small and comprised of only $1-2$ atoms and a mean diameter of $0.40 \pm 0.05 \mathrm{~nm}$. When $\mathrm{KNO}_{3}$ is used as a sacrificial acceptor to promote $\mathrm{IrO}_{x}$ growth, ${ }^{23}$ the particles are slightly larger at $\sim 0.67 \pm 0.76 \mathrm{~nm}$ mean diameter corresponding to $<20 \mathrm{Ir}$ atoms. The particle density is not affected by $\mathrm{KNO}_{3}$. On the bulk niobate, the mean particle size is slightly larger, with mean diameters ranging from $0.75 \pm 0.31 \mathrm{~nm}$ (no $\mathrm{KNO}_{3}$ ) to $0.72 \pm 0.17 \mathrm{~nm}$ (with $\mathrm{KNO}_{3}$ ). In both cases, particles are evenly distributed on the surfaces of the crystals.

To evaluate the photocatalytic properties of the materials, over 30 irradiation experiments were performed on catalysts 


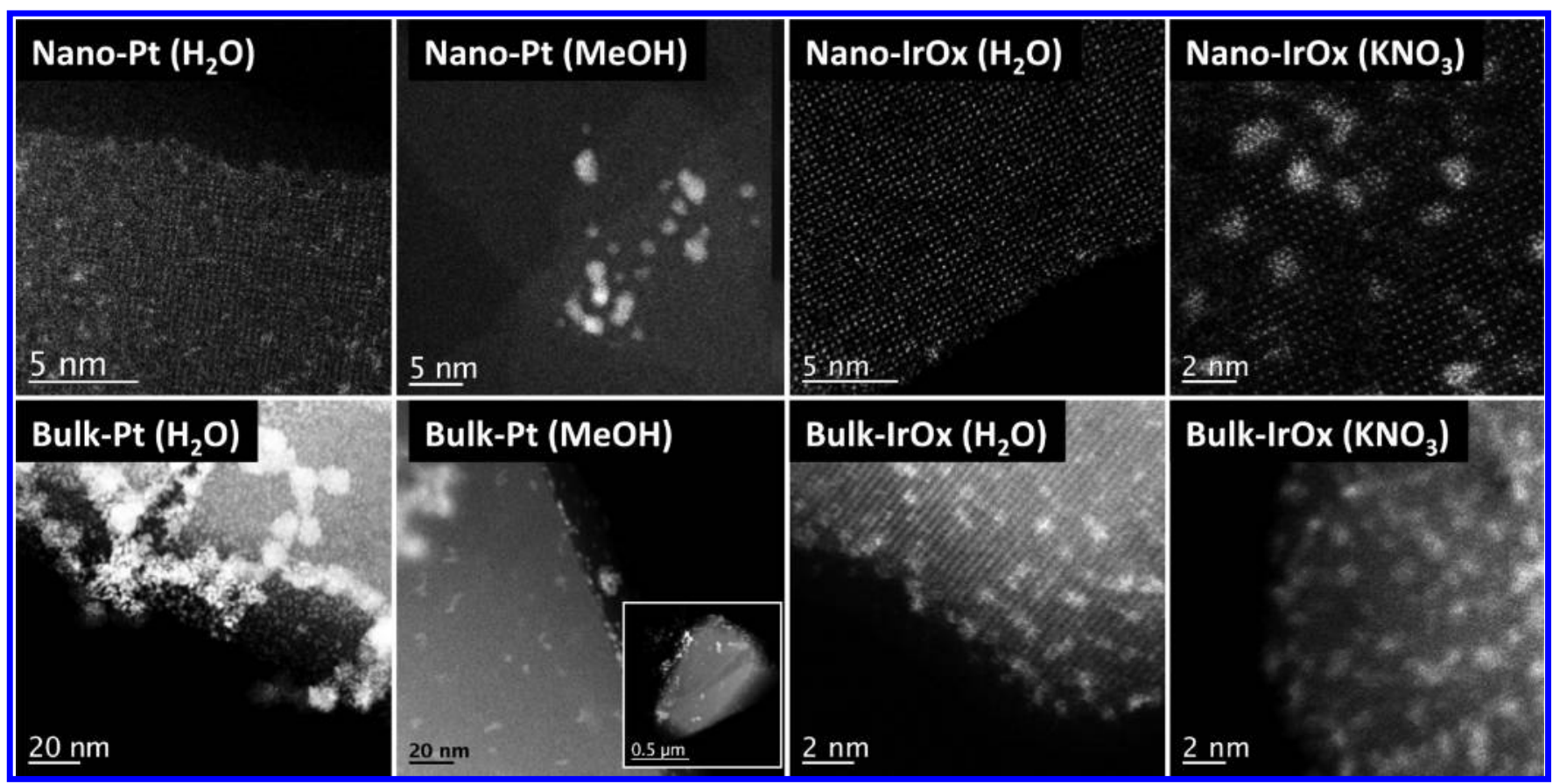

Figure 3. HAADF-STEM micrographs of modified bulk and nanoniobates.

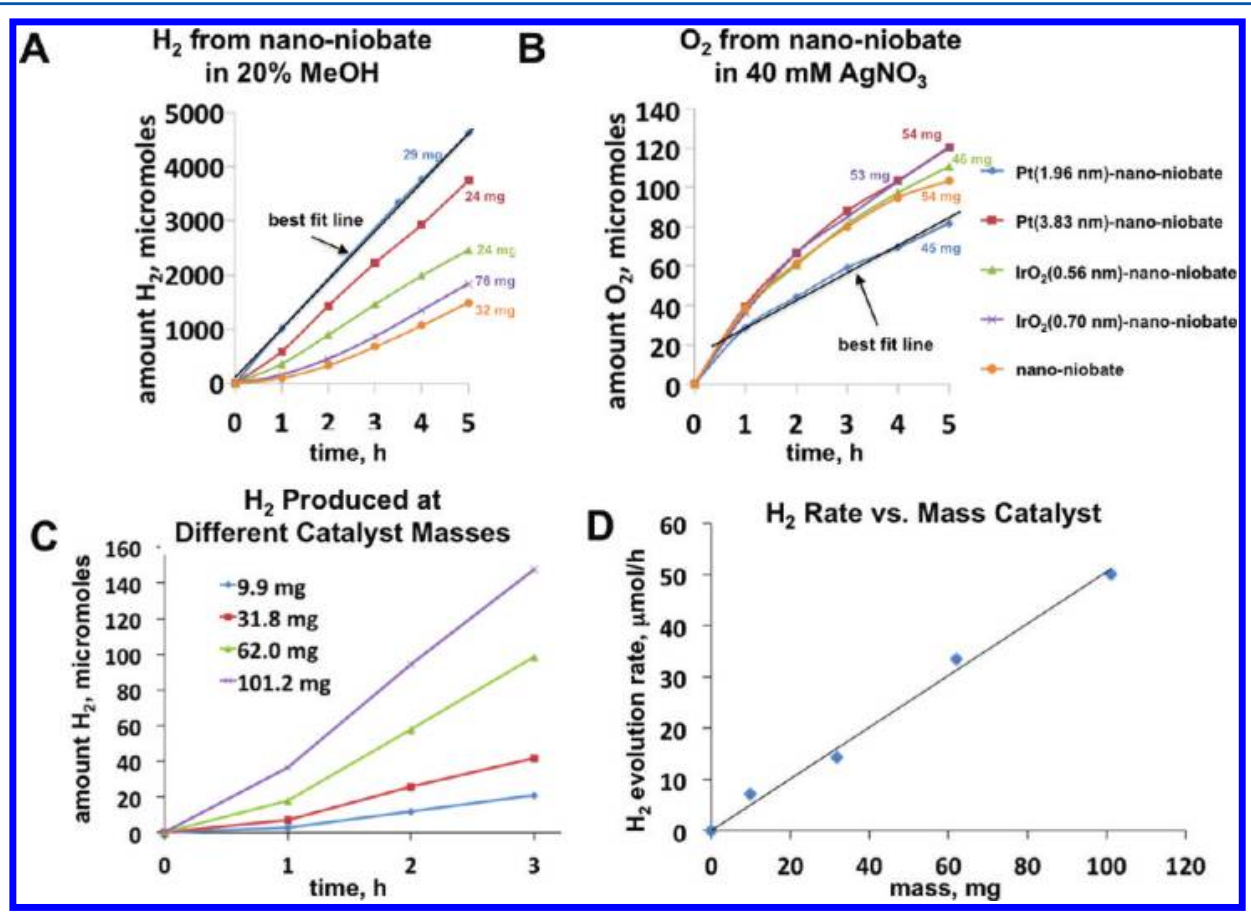

Figure 4. (A) $\mathrm{H}_{2}$ evolution rates from modified nanoniobates in 20 vol \% aqueous $\mathrm{MeOH},(\mathrm{B}) \mathrm{O}_{2}$ evolution rates from modified nanoniobates in 40 $\mathrm{mM}$ aqueous $\mathrm{AgNO}_{3}$, (C) $\mathrm{H}_{2}$ produced with different amounts of nanoniobate from $20 \mathrm{vol} \%$ aqueous $\mathrm{MeOH}$, and (D) plot of $\mathrm{H}_{2}$ evolution rate vs catalyst mass. Irradiation was from a $300 \mathrm{~W}$ Cermax PE300BUV Xe lamp.

(25-100 mg mass) dispersed in water, in aqueous silver nitrate and methanol solutions, with full spectral illumination $(>250 \mathrm{~nm})$ from a $300 \mathrm{~W}$ Xe arc lamp, equipped with an infrared filter. Hydrogen and oxygen evolution data from solutions of sacrificial agents are shown in Figure 4, and data from pure water are shown in Figure S-3 (Supporting Information). On the basis of repeat measurements, we estimate the error in gas amounts to be $<20 \%$. In methanol solution, $\mathrm{H}_{2}$ evolution was found to be linear over time (Figure 4A) and to scale proportionally with catalyst mass (Figure 4C,D). This provides the justification for normalizing the rates according to catalyst mass (see below). As expected, no $\mathrm{H}_{2}$ was evolved from any of the catalysts in the presence of the electron acceptor $\mathrm{AgNO}_{3}$, and no $\mathrm{O}_{2}$ was evolved in the presence of the electron donor $\mathrm{MeOH}$. In pure water, initial $\mathrm{H}_{2}$ evolution was observed at low rate and with steady decline over time (Figure S-3, Supporting Information) because the catalyst becomes deactivated by surface bound peroxides. ${ }^{13,19}$ For $\mathrm{O}_{2}$ evolution from aqueous $\mathrm{AgNO}_{3}$, a similar loss in activity over time (Figure $4 \mathrm{~B}$ ) is due to poisoning of the catalyst surface with photoreduced Ag. ${ }^{21,24,25}$ 


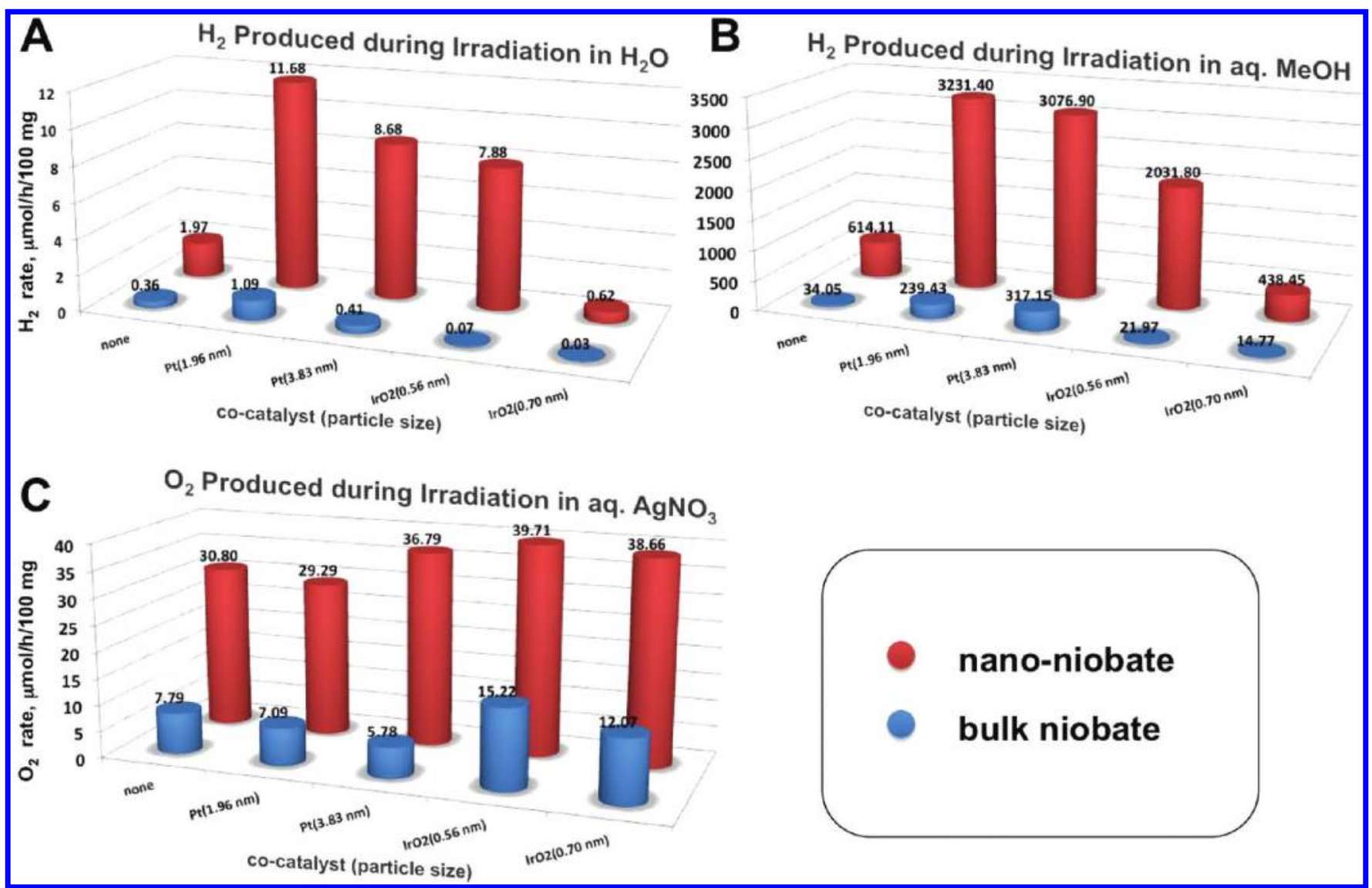

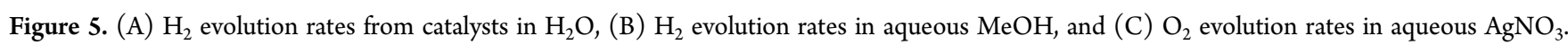

In this case, rates for oxygen gas evolution were obtained from the most linear portion of the graph, when silver deposition is not yet affecting the gas evolution rate.

The normalized rates for all tested catalysts (per $0.1 \mathrm{~g}$ of catalyst) are summarized in Figure 5 and Table 1. These data allow the following observations. First, for both $\mathrm{H}_{2}$ and $\mathrm{O}_{2}$, the nanoniobate shows consistently higher evolution rates than the bulk form. Second, $\mathrm{H}_{2}$ rates are higher upon irradiation in aqueous methanol than in water, and $\mathrm{O}_{2}$ is being produced only in the presence of $\mathrm{AgNO}_{3}$. For the nanoniobate, the addition of cocatalysts generally increases activity, with the exception of IrOx, while for the bulk niobate both $\mathrm{Pt}$ and IrOx cocatalysts can lead to reduced performance.

To quantitatively analyze the results in Figure 5, a factorial analysis (additional details in Supporting Information) was carried out on the calculated evolution rates from all irradiation experiments. Results were averaged for each variable under the four experimental factors (catalyst size, sacrificial agents, cocatalysts, and cocatalyst size). The strength of each of the factors was then quantified by the $p$ value calculated from the analysis of variance (ANOVA) of the grouped means. Lower $p$ values indicate stronger factors, with $p$ values $<0.05$ indicating at least $95 \%$ confidence level $(p=0.95)$. Effects plots for $\mathrm{H}_{2}$ and $\mathrm{O}_{2}$ evolution are shown in Figures 5 and 6 .

For both $\mathrm{H}_{2}$ and $\mathrm{O}_{2}$ evolution, sacrificial donors show the strongest effects (Figures 6A and 7A, $p=0.008$ for $\mathrm{H}_{2}$ activity and $p=0$ for $\mathrm{O}_{2}$ ) on the activity of both nano- and bulk niobate. The presence of methanol is required to obtain stable catalytic $\mathrm{H}_{2}$ evolution because of the tendency of these catalysts to generate peroxides upon irradiation from water. ${ }^{19}$ Only very little $\mathrm{H}_{2}$ is evolved from $\mathrm{H}_{2} \mathrm{O}$, and $\mathrm{O}_{2}$ evolution only occurs in the presence of $\mathrm{AgNO}_{3}$. The effect of niobate particle size (Figures $5 \mathrm{~B}$ and $6 \mathrm{~B}$ ) is statistically very significant with $p=$ 0.010 and $p=0$, respectively. On average, the nanoniobate produces 16 times more hydrogen and 8 times more oxygen than the bulk niobate (see inset in Figures $6 \mathrm{~A} / 7 \mathrm{~A}$ ).

The effect of the cocatalysts on $\mathrm{H}_{2}$ and $\mathrm{O}_{2}$ production is shown in Figures 6C and 7C. For both nano- and bulk niobate, platinum contributes a 5-fold increase in $\mathrm{H}_{2}$ activity over the bare niobates (average of $\mathrm{H}_{2} \mathrm{O}$ and methanol). The addition of iridium oxide, $\mathrm{IrO}_{x}$, a cocatalyst for water oxidation, also shows a small $(20 \%)$ contribution to $\mathrm{H}_{2}$ production. For this reason, cocatalyst deposition fails the significance test $(p=0.113)$ as deposition of either cocatalyst results in an increase in $\mathrm{H}_{2}$ activity even if $\mathrm{Pt}$ does more so. When the effect of $\mathrm{IrO}_{x}$ on $\mathrm{H}_{2}$ production is analyzed separately for bulk and nanoniobate, however, only the nanoniobate shows improved $\mathrm{H}_{2}$ production, whereas on the bulk niobate $\mathrm{IrO}_{x}$ diminishes $\mathrm{H}_{2}$ production. As for $\mathrm{O}_{2}(p=0.021)$, the presence of $\mathrm{IrO}_{x}$ increases activity by $43 \%$, while Pt diminishes activity by $10 \%$ compared to the bare catalysts.

Finally, we consider the effect of the size of the cocatalyst particles. Compared to the other factors, the effect of cocatalyst particle size has a large statistical error $\left(p=0.388\right.$ for $\mathrm{H}_{2}$ activity and $p=0.814$ for $\mathrm{O}_{2}$ activity). The smaller cocatalyst particles $\left(1.96 \mathrm{~nm} \mathrm{Pt}\right.$ and $0.57 \mathrm{~nm} \mathrm{IrO}_{x}$ ) are $44 \%$ more active for $\mathrm{H}_{2}$ production than the larger particles. The size effect is stronger for the nanoniobate (factor of 20 difference between small and large particles) than for the bulk phase. For $\mathrm{O}_{2}$ production, the effect of cocatalyst sizes is not significant, which indicates that other factors are limiting. 
Table 1. $\mathrm{H}_{2}$ and $\mathrm{O}_{2}$ Evolution Rates under UV/vis Illumination, Normalized to $100 \mathrm{mg}$ of Catalyst Mass

\begin{tabular}{|c|c|c|c|c|c|}
\hline catalyst & irradiation solvent & cocatalyst & cocatalyst size $(\mathrm{nm})$ & $\mathrm{H}_{2}$ rate $(\mu \mathrm{mol} / \mathrm{h})$ & $\mathrm{O}_{2}$ rate $(\mu \mathrm{mol} / \mathrm{h})$ \\
\hline $\mathrm{TBACa}_{2} \mathrm{Nb}_{3} \mathrm{O}_{10}$ & $\mathrm{H}_{2} \mathrm{O}$ & -- & -- & 1.97 & 0.00 \\
\hline $\mathrm{TBACa}_{2} \mathrm{Nb}_{3} \mathrm{O}_{10}$ & $\mathrm{H}_{2} \mathrm{O}$ & $2 \% \mathrm{Pt}$ & 1.96 & 11.68 & 0.00 \\
\hline $\mathrm{TBACa}_{2} \mathrm{Nb}_{3} \mathrm{O}_{10}$ & $\mathrm{H}_{2} \mathrm{O}$ & $2 \% \mathrm{Pt}$ & 3.83 & 8.68 & 0.00 \\
\hline $\mathrm{TBACa}_{2} \mathrm{Nb}_{3} \mathrm{O}_{10}$ & $\mathrm{H}_{2} \mathrm{O}$ & $2 \% \mathrm{IrO}_{x}$ & 0.56 & 7.88 & 0.00 \\
\hline $\mathrm{TBACa}_{2} \mathrm{Nb}_{3} \mathrm{O}_{10}$ & $\mathrm{H}_{2} \mathrm{O}$ & $2 \% \mathrm{IrO}_{x}$ & 0.70 & 0.62 & 0.00 \\
\hline $\mathrm{TBACa}_{2} \mathrm{Nb}_{3} \mathrm{O}_{10}$ & $20 \% \mathrm{MeOH}$ & -- & -- & 614.11 & 0.00 \\
\hline $\mathrm{TBACa}_{2} \mathrm{Nb}_{3} \mathrm{O}_{10}$ & $20 \% \mathrm{MeOH}$ & $2 \% \mathrm{Pt}$ & 1.96 & 3231.40 & 0.00 \\
\hline $\mathrm{TBACa}_{2} \mathrm{Nb}_{3} \mathrm{O}_{10}$ & $20 \% \mathrm{MeOH}$ & $2 \% \mathrm{Pt}$ & 3.83 & 3076.90 & 0.00 \\
\hline $\mathrm{TBACa}_{2} \mathrm{Nb}_{3} \mathrm{O}_{10}$ & $20 \% \mathrm{MeOH}$ & $2 \% \mathrm{IrO}_{x}$ & 0.56 & 2031.80 & 0.00 \\
\hline $\mathrm{TBACa}_{2} \mathrm{Nb}_{3} \mathrm{O}_{10}$ & $20 \% \mathrm{MeOH}$ & $2 \% \mathrm{IrO}_{x}$ & 0.70 & 438.45 & 0.00 \\
\hline $\mathrm{TBACa}_{2} \mathrm{Nb}_{3} \mathrm{O}_{10}$ & $40 \mathrm{mM} \mathrm{AgNO} 3$ & -- & -- & 0.00 & 30.80 \\
\hline $\mathrm{TBACa}_{2} \mathrm{Nb}_{3} \mathrm{O}_{10}$ & $40 \mathrm{mM} \mathrm{AgNO} 3$ & $2 \% \mathrm{Pt}$ & 1.96 & 0.00 & 29.29 \\
\hline $\mathrm{TBACa}_{2} \mathrm{Nb}_{3} \mathrm{O}_{10}$ & $40 \mathrm{mM} \mathrm{AgNO} 3$ & $2 \% \mathrm{Pt}$ & 3.83 & 0.00 & 36.79 \\
\hline $\mathrm{TBACa}_{2} \mathrm{Nb}_{3} \mathrm{O}_{10}$ & $40 \mathrm{mM} \mathrm{AgNO} 3$ & $2 \% \mathrm{IrO}_{x}$ & 0.56 & 0.00 & 39.71 \\
\hline $\mathrm{TBACa}_{2} \mathrm{Nb}_{3} \mathrm{O}_{10}$ & $40 \mathrm{mM} \mathrm{AgNO}$ & $2 \% \mathrm{IrO}_{x}$ & 0.70 & 0.00 & 38.66 \\
\hline $\mathrm{KCa}_{2} \mathrm{Nb}_{3} \mathrm{O}_{10}$ & $\mathrm{H}_{2} \mathrm{O}$ & -- & -- & 0.36 & 0.00 \\
\hline $\mathrm{KCa}_{2} \mathrm{Nb}_{3} \mathrm{O}_{10}$ & $\mathrm{H}_{2} \mathrm{O}$ & $2 \% \mathrm{Pt}$ & 1.96 & 1.09 & 0.00 \\
\hline $\mathrm{KCa}_{2} \mathrm{Nb}_{3} \mathrm{O}_{10}$ & $\mathrm{H}_{2} \mathrm{O}$ & $2 \% \mathrm{Pt}$ & 3.83 & 0.41 & 0.00 \\
\hline $\mathrm{KCa}_{2} \mathrm{Nb}_{3} \mathrm{O}_{10}$ & $\mathrm{H}_{2} \mathrm{O}$ & $2 \% \mathrm{IrO}_{x}$ & 0.56 & 0.07 & 0.00 \\
\hline $\mathrm{KCa}_{2} \mathrm{Nb}_{3} \mathrm{O}_{10}$ & $\mathrm{H}_{2} \mathrm{O}$ & $2 \% \mathrm{IrO}_{x}$ & 0.70 & 0.03 & 0.00 \\
\hline $\mathrm{KCa}_{2} \mathrm{Nb}_{3} \mathrm{O}_{10}$ & $20 \% \mathrm{MeOH}$ & -- & -- & 34.05 & 0.00 \\
\hline $\mathrm{KCa}_{2} \mathrm{Nb}_{3} \mathrm{O}_{10}$ & $20 \% \mathrm{MeOH}$ & $2 \% \mathrm{Pt}$ & 1.96 & 239.43 & 0.00 \\
\hline $\mathrm{KCa}_{2} \mathrm{Nb}_{3} \mathrm{O}_{10}$ & $20 \% \mathrm{MeOH}$ & $2 \% \mathrm{Pt}$ & 3.83 & 317.15 & 0.00 \\
\hline $\mathrm{KCa}_{2} \mathrm{Nb}_{3} \mathrm{O}_{10}$ & $20 \% \mathrm{MeOH}$ & $2 \% \operatorname{IrO}_{x}$ & 0.56 & 21.97 & 0.00 \\
\hline $\mathrm{KCa}_{2} \mathrm{Nb}_{3} \mathrm{O}_{10}$ & $20 \% \mathrm{MeOH}$ & $2 \% \mathrm{IrO}_{x}$ & 0.70 & 14.77 & 0.00 \\
\hline $\mathrm{KCa}_{2} \mathrm{Nb}_{3} \mathrm{O}_{10}$ & $40 \mathrm{mM} \mathrm{AgNO}{ }_{3}$ & -- & -- & 0.00 & 7.79 \\
\hline $\mathrm{KCa}_{2} \mathrm{Nb}_{3} \mathrm{O}_{10}$ & $40 \mathrm{mM} \mathrm{AgNO}$ & $2 \% \mathrm{Pt}$ & 1.96 & 0.00 & 7.09 \\
\hline $\mathrm{KCa}_{2} \mathrm{Nb}_{3} \mathrm{O}_{10}$ & $40 \mathrm{mM} \mathrm{AgNO}_{3}$ & $2 \% \mathrm{Pt}$ & 3.83 & 0.00 & 5.78 \\
\hline $\mathrm{KCa}_{2} \mathrm{Nb}_{3} \mathrm{O}_{10}$ & $40 \mathrm{mM} \mathrm{AgNO}$ & $2 \% \mathrm{IrO}_{x}$ & 0.56 & 0.00 & 15.22 \\
\hline $\mathrm{KCa}_{2} \mathrm{Nb}_{3} \mathrm{O}_{10}$ & $40 \mathrm{mM} \mathrm{AgNO}$ & $2 \% \mathrm{IrO}_{x}$ & 0.70 & 0.00 & 12.07 \\
\hline
\end{tabular}

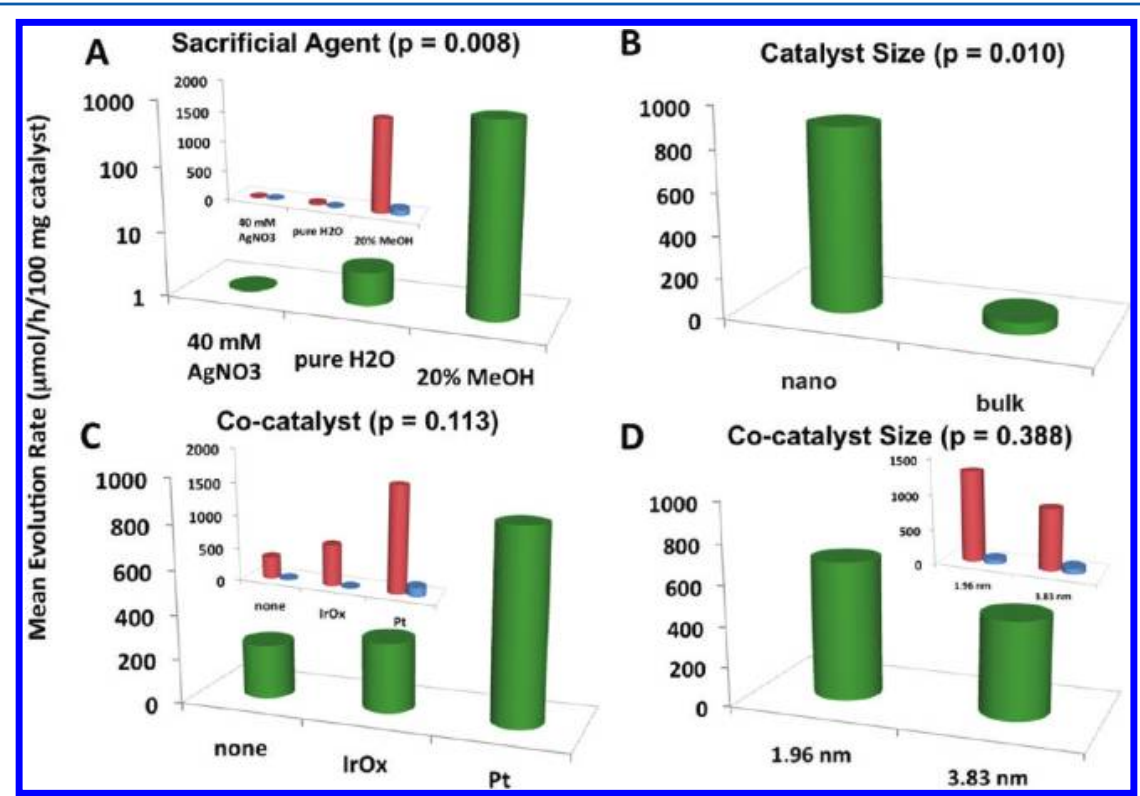

Figure 6. Effects plots for hydrogen evolution. (A) Sacrificial agents during irradiation, (B) catalyst size, (C) cocatalyst, and (D) cocatalyst particle size (averages for $\mathrm{Pt}$ and $\mathrm{IrO}_{x}$ ). Insets: effects plots grouped by catalysts, bulk (blue), and nanoniobate (red).

To rationalize the observed differences in catalytic activity between the nano- and the bulk materials and their various $\mathrm{Pt} /$ $\mathrm{IrO}_{x}$-modified forms, we perform a kinetic analysis of the processes and parameters involved in catalytic turnover. The kinetic model illustrated in Figure 8 and expressed in eq 1 is a simplified form of the one-dimensional continuity equation for illuminated semiconductors. ${ }^{26-30}$ In the model, the activity of the suspended catalyst particles is considered a result of the generation of photochemical charge carriers at rate $R_{\mathrm{G}}$, which depends on flux and light absorption of the catalyst. The carriers move to the surface at transfer flux $J_{\mathrm{CT}}$ for holes and electrons, respectively, traversing the distance $r$ between generation sites 


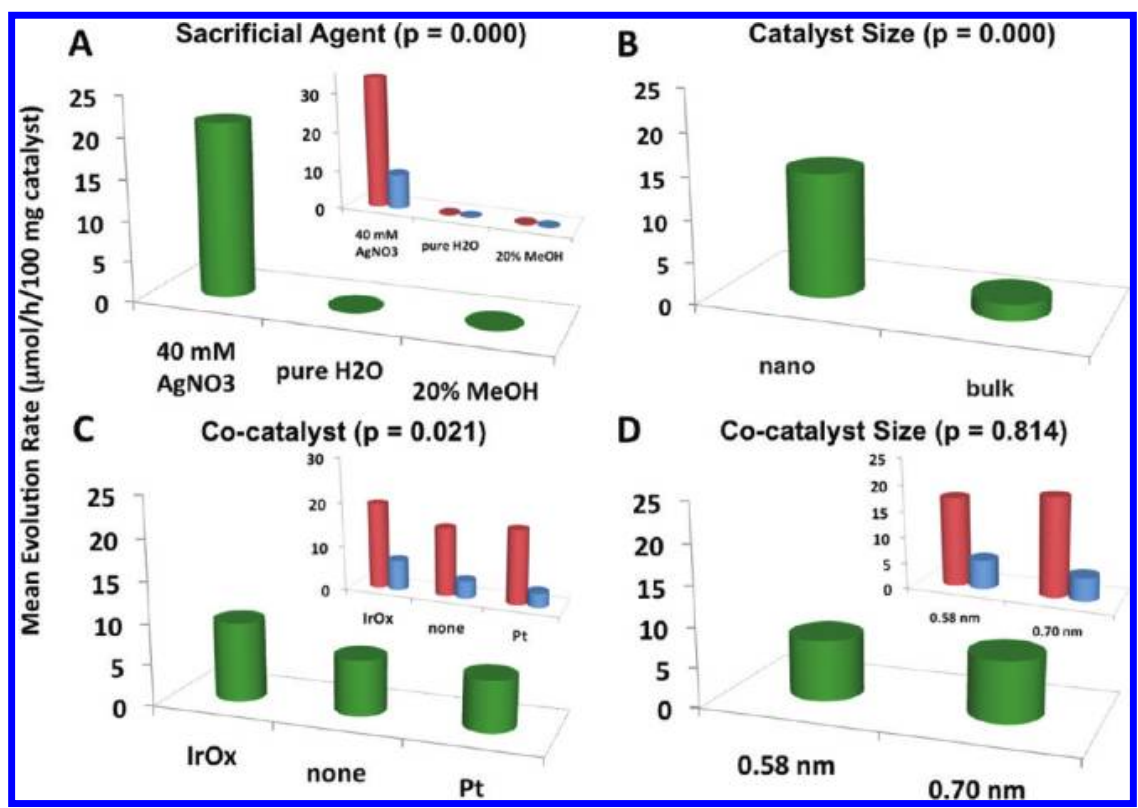

Figure 7. Main effects plots for oxygen evolution. (A) Sacrificial agents during irradiation, (B) catalyst size, (C) cocatalyst, and (D) cocatalyst particle size. Insets: effects plots grouped by catalysts, bulk (blue), and nanoniobate (red).

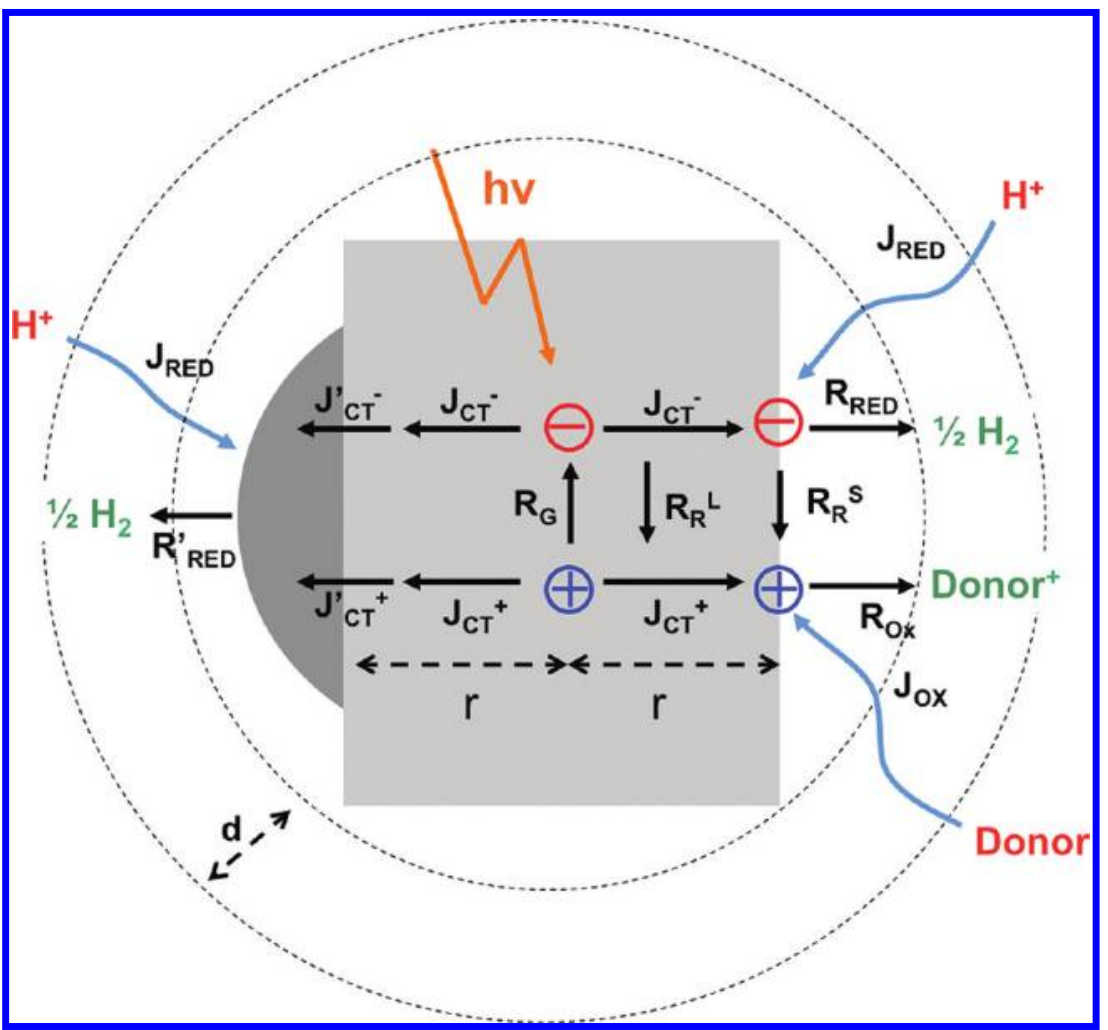

Figure 8. Kinetic model for water splitting photocatalysis with suspended semiconductor particles. The model calculates the electronic rate of the catalyst $\left(\mathrm{mol} \mathrm{s}^{-1} \mathrm{~cm}^{-3}\right)$ from the rates for light-induced e/h generation $\left(R_{\mathrm{G}}\right)$ and e/h recombination in the lattice $\left(R_{\mathrm{R}}{ }^{\mathrm{L}}\right)$ and on the surface $\left(R_{\mathrm{R}}^{\mathrm{S}}\right)$, from the rates for charge and mass transfer to the catalyst-water interface $\left(J_{\mathrm{CT}}, J_{\mathrm{RED} / \mathrm{OX}}\right)$, and from the rates for the redox reactions with the substrates $\left(R_{\mathrm{RED}}, R_{\mathrm{OX}}\right)$. Numerical values for these rates and further descriptions are given in Table 2 .

and surface sites. In contrast to the earlier work, no assumptions are made about the transfer mechanism, i.e., diffusion or drift. Charge transfer occurs in competition to charge recombination at rate $R_{\mathrm{R}}{ }^{\mathrm{L}}$ in the lattice and rate $R_{\mathrm{R}}{ }^{\mathrm{S}}$ at the surface. On the surface, reactions with sacrificial agents and water proceed at rates $R_{\mathrm{Red}}$ and $R_{\mathrm{Ox}}$. If cocatalysts (Pt or $\mathrm{IrO}_{x}$ ) are present, charge transfer rates are modified to $R_{\text {Red }}^{\prime}$ and $R_{\mathrm{Ox}}^{\prime}$.
Under these conditions, charges need to cross the semiconductor-cocatalyst interface at fluxes $\mathrm{J}_{\mathrm{CT}}^{\prime}{ }^{+}$and $\mathrm{J}_{\mathrm{CT}}^{\prime}$, respectively. If these fluxes differ among electrons and holes, i.e., the interface is rectifying, charges are separated at the interface, effectively reducing e/h recombination rates $R_{\mathrm{R}}{ }^{\mathrm{L}}$. In the regime of fast catalyst turnover and low substrate concentration, solution mass transport at flux $J_{\mathrm{RED}}$ and $J_{\mathrm{OX}}$ can 
Table 2. Kinetic Parameters of Catalysts

\begin{tabular}{|c|c|c|c|c|c|c|c|}
\hline & $\begin{array}{l}\text { observed gas } \\
\text { formation rate }\end{array}$ & $\begin{array}{l}\text { electronic rate } \\
\mathrm{ER}^{b}\end{array}$ & $\begin{array}{l}\text { measured } \\
\text { flux }^{c}\end{array}$ & $\begin{array}{c}\text { apparent } \\
\text { generation rate } \\
R_{\mathrm{G}}{ }^{d}\end{array}$ & $\begin{array}{l}\text { apparent quantum } \\
\text { efficiency }(\mathrm{AQE})^{e}\end{array}$ & $\begin{array}{l}\text { recombination } \\
\text { rate } R_{\mathrm{R}}^{f}\end{array}$ & $\begin{array}{l}\text { inverse charge diffusion } \\
\text { pathlength } r^{-1 g}\end{array}$ \\
\hline system & $\begin{array}{l}{\left[\mathrm{mol} \mathrm{h}^{-1} \text { per }\right.} \\
100 \mathrm{mg}]\end{array}$ & {$\left[\mathrm{mol} \mathrm{s}^{-1} \mathrm{~cm}^{-3}\right]$} & {$\left[\mathrm{mol} \mathrm{s}^{-1}\right]$} & {$\left[\mathrm{mol} \mathrm{s}^{-1} \mathrm{~cm}^{-3}\right]$} & [\%] & {$\left[\mathrm{mol} \mathrm{s}^{-1} \mathrm{~cm}^{-3}\right]$} & {$\left[\mathrm{cm}^{-1}\right]$} \\
\hline bulk in water & $3.60 \times 10^{-7}$ & $8.40 \times 10^{-9}$ & $2.64 \times 10^{-6}$ & $1.11 \times 10^{-4}$ & 0.00 & $1.11 \times 10^{-4}$ & $8.8 \times 10^{4}$ \\
\hline nano in water & $1.97 \times 10^{-6}$ & $4.60 \times 10^{-8}$ & $2.64 \times 10^{-6}$ & $1.11 \times 10^{4}$ & 0.02 & $1.11 \times 10^{-4}$ & $1.8 \times 10^{7}$ \\
\hline $\begin{array}{l}\text { bulk in } \\
\mathrm{AgNO}_{3}\end{array}$ & - & - & $2.64 \times 10^{-6}$ & $1.11 \times 10^{-4}$ & - & $1.11 \times 10^{-4}$ & $8.8 \times 10^{4}$ \\
\hline $\begin{array}{l}\text { nano in } \\
\mathrm{AgNO}_{3}\end{array}$ & $3.08 \times 10^{-5}$ & $1.44 \times 10^{-6}$ & $2.64 \times 10^{-6}$ & $1.11 \times 10^{-4}$ & 0.32 & $1.09 \times 10^{-4}$ & $1.8 \times 10^{7}$ \\
\hline $\begin{array}{l}\text { bulk in } \\
\mathrm{MeOH}\end{array}$ & $3.41 \times 10^{-5}$ & $7.96 \times 10^{-7}$ & $2.64 \times 10^{-6}$ & $1.11 \times 10^{-4}$ & 0.36 & $1.10 \times 10^{-4}$ & $8.8 \times 10^{4}$ \\
\hline $\begin{array}{c}\text { nano in } \\
\mathrm{MeOH}\end{array}$ & 0.000614 & $1.43 \times 10^{-5}$ & $2.64 \times 10^{-6}$ & $1.11 \times 10^{-4}$ & 6.46 & $9.66 \times 10^{-5}$ & $1.8 \times 10^{7}$ \\
\hline $\begin{array}{l}\text { bulk Pt in } \\
\mathrm{MeOH}\end{array}$ & $2.39 \times 10^{-4}$ & $5.58 \times 10^{-6}$ & $2.64 \times 10^{-6}$ & $1.11 \times 10^{-4}$ & 2.51 & $1.05 \times 10^{-4}$ & $8.8 \times 10^{4}$ \\
\hline $\begin{array}{c}\text { nano-Pt in } \\
\mathrm{MeOH}\end{array}$ & $3.23 \times 10^{-3}$ & $7.54 \times 10^{-5}$ & $2.64 \times 10^{-6}$ & $1.11 \times 10^{4}$ & 34.0 & $3.55 \times 10^{-5}$ & $1.8 \times 10^{7}$ \\
\hline
\end{tabular}

${ }^{a}$ From Table 1 in moles of product, per hour, and per $100 \mathrm{mg}$ of catalyst. ${ }^{b}$ Electrons/holes turned over per second and per cubic centimeter of catalyst. ${ }^{c}$ Integrated over the $250-380 \mathrm{~nm}$ regime, using $315 \mathrm{~nm}$ as mean wavelength. ${ }^{d}$ Same for bulk and nano. ${ }^{e} \mathrm{Calculated}$ as ratio of ER and RG, divided by the number of electrons/holes per molecule of formed $\mathrm{H}_{2} / \mathrm{O}_{2} \cdot{ }^{f}$ Calculated from difference of $R_{\mathrm{G}}$ and ER. Includes lattice and surface recombination. ${ }^{g}$ Determined from niobate particle sizes.

theoretically become rate limiting. In that case, a diffusion layer of thickness $d$ will form around the catalyst. Back reactions (oxidation of $\mathrm{H}_{2}$ or reduction of $\mathrm{O}_{2}$ ) can be ignored, based on the linearity of the gas evolution and the absence of saturation effects in the studied time intervals.

Analytically, the model is expressed through eq 1 , which calculates the electronic rate ER, i.e., the number of reacted electrons/holes normalized to cubic centimeter of catalyst and per second, from the rates of the underlying individual processes (for values see Table 2). Thus, ER will be limited by the smallest term in the equation.

$$
\begin{aligned}
\mathrm{ER}= & R_{\mathrm{G}} \frac{1}{{R_{\mathrm{R}}}^{\mathrm{L}}+R_{\mathrm{R}}^{\mathrm{S}}} \frac{J_{\mathrm{CT}}}{r} \frac{J_{\mathrm{CT}}{ }^{+}}{r} \\
& \times R_{\mathrm{RED}} R_{\mathrm{OX}}\left(\frac{J_{\mathrm{RED}}}{d_{\mathrm{RED}}} \frac{J_{\mathrm{OX}}}{d_{\mathrm{OX}}}\right)
\end{aligned}
$$

Table 2 provides a summary of calculated and estimated values for the terms in eq 1 , using the experimentally observed $\mathrm{H}_{2} / \mathrm{O}_{2}$ gas evolution rates $\left[\mathrm{mol} \mathrm{H}_{2} \mathrm{~h}^{-1} / 0.1 \mathrm{~g}\right.$ of catalyst] in Table 1 as a starting point. In column 2 , these rates are converted into electronic rate (ER) values $\left[\mathrm{mol} \mathrm{s}^{-1} \mathrm{~cm}^{-3}\right]$. The flux of the $300 \mathrm{~W}$ Xe lamp is shown in column 3. A value of $2.64 \times 10^{-6} \mathrm{~mol} \mathrm{~s}^{-1}$ was estimated assuming that irradiation is monochromatic at $315 \mathrm{~nm}$. This wavelength corresponds to the mean of the detection range of the $\mathrm{GaN}$ photodector $(250-380 \mathrm{~nm}$, measured power of $26.3 \mathrm{~mW} / \mathrm{cm}^{2}$ at the flask) and the absorption range of the photocatalysts. To calculate the apparent volumetric charge carrier generation rate $R_{\mathrm{G}}$ in column 4 , we assume that all photons are absorbed by $100 \mathrm{mg}$ of the suspended niobate particles in $100 \mathrm{~mL}$ of the solvent. Particles can be considered fully illuminated in the center (no internal particle shading), based on the optical absorption coefficient for $\mathrm{KCa}_{2} \mathrm{Nb}_{3} \mathrm{O}_{10}$ of $\alpha=0.200 \mathrm{~cm}^{-1}$ (at $280 \mathrm{~nm}$, Figure S-4, Supporting Information), which predicts significant light attenuation (shading) only for large particles (above $1.0 \mathrm{~cm}$ edge size). The bulk particles used in the experiments have a thickness of $227 \pm 202 \mathrm{~nm}$ (SEM images in Figure 2 and
Figure S-2, Supporting Information), whereas the nanoniobate particles were only $1.1 \mathrm{~nm}$ thick (from TEM images in Figure 2 and crystal structure). Using a density of $4.2 \mathrm{~g} \mathrm{~cm}^{-3}$ for the catalysts, $R_{\mathrm{G}}$ can be estimated as $1.11 \times 10^{-4} \mathrm{~mol} \mathrm{~s}^{-1} \mathrm{~cm}^{-3}$ for bulk and nanoniobate. Knowing $R_{\mathrm{G}}$ and $\mathrm{ER}$, the apparent quantum efficiency AQE can be calculated for the different catalysts in data column 5, after adjusting for the number of electron/holes required to generate product (two electrons for $\mathrm{H}_{2}$ and four holes for $\mathrm{O}_{2}$ ). Calculated AQE values are found between 0 (for the nanoniobate in water) and $34 \%$ (for the nanoniobate with Pt in aqueous methanol), which compares well with our previous measurements for similar systems. ${ }^{18,20}$ The difference between the electronic rate ER and the generation rate $R_{\mathrm{G}}$ gives the volumetric charge recombination rate $R_{\mathrm{R}}$ in column 6 . This assumes that $R_{\mathrm{G}}=\mathrm{ER}+R_{\mathrm{R}}$, i.e., that all photogenerated charge carriers either react with the substrate or recombine. Comparing $R_{\mathrm{R}}$ values between nanoand bulk niobate, no obvious difference in the recombination rate is found in water. However, the introduction of methanol and of the Pt cocatalysts leads to significantly decreased recombination in the nanoniobate (and increased $\mathrm{H}_{2}$ evolution activity). The reduced recombination rate in the nanoniobate compared to the bulk is surprising considering the higher specific surface area, which should increase the surface recombination rate. ${ }^{31}$ On the basis of particle sizes, the specific surface area of the nanoniobate $\left(S_{\text {nano }}=4.3 \times 10^{6} \mathrm{~cm}^{2} \mathrm{~g}^{-1}\right.$, details in Supporting Information) is 69 times higher than that of bulk niobate $\left(S_{\text {bulk }}=6.3 \times 10^{4} \mathrm{~cm}^{2} \mathrm{~g}^{-1}\right)$. The lower recombination rate for the nanomaterial is likely due to the laminar structure of the niobate, which corresponds to low energy surfaces with low defect concentrations. Recombination is further decreased because of improved charge transport from the particle interior to the catalyst-water interface. In eq 1 , the volumetric charge transport rate $\left[\mathrm{mol} \mathrm{s}^{-1} \mathrm{~cm}^{-3}\right]$ is defined as the ratio of the charge flux $J_{\mathrm{CT}}\left[\mathrm{mol} \mathrm{s} \mathrm{cm}^{-1}\right]$ and the average charge transfer distance $r[\mathrm{~cm}]$. Because numerical values for $J_{\mathrm{CT}}$ are not available, the following discussion will be based on the inverse charge transfer distance $r^{-1}\left[\mathrm{~cm}^{-1}\right]$ instead (column 7). In the nanoniobate, all photochemical charge carriers are generated 
directly on the nanosheet surface or within $0.55 \mathrm{~nm}$ from it (half of $1.1 \mathrm{~nm}$ thickness), practically eliminating delays from charge transport to the surface. The inverse charge transfer distance $r^{-1}$ in this case equals $\left(0.55 \times 10^{-7}\right)^{-1} \mathrm{~cm}^{-1}=1.8 \times 10^{7}$ $\mathrm{cm}^{-1}$. In the bulk niobate, on the other hand, charge carriers have to travel substantially further (half of $227 \pm 202 \mathrm{~nm}$ ) before they reach the nearest surface site. Thus, $r^{-1}$ is much smaller, about $\left(114 \times 10^{-7}\right)^{-1} \mathrm{~cm}^{-1}=8.8 \times 10^{4} \mathrm{~cm}^{-1}$. Therefore, solely based on size arguments, charge transport to the surface is estimated to be over 200 times faster in the nanoniobate than in the bulk niobate. This difference explains the higher activity of the nanoparticles and their lower recombination rate compared to the bulk.

From previous electrochemical measurements on the nanoniobate sheets and the related hexaniobate $\left(\mathrm{H}_{2} \mathrm{~K}_{2} \mathrm{Nb}_{6} \mathrm{O}_{17}\right)$ nanoscrolls, ${ }^{13,20}$ which reveal a correlation between the electrochemical redox overpotentials and the photocatalytic activity, it can be inferred that the catalytic rate for the niobates is limited by the slow redox kinetics of the catalyst. For example, Pt was found to lower the proton reduction potential of the nanoniobate by $260 \mathrm{mV}^{20}$ and to increase the $\mathrm{H}_{2}$ activity 5-fold (from 614 to $3077 \mu \mathrm{mol} \mathrm{h}^{-1} 100 \mathrm{mg}^{-1}$ ) in aqueous methanol. Similarly, the addition of $\mathrm{IrO}_{x}$ particles reduced the $\mathrm{H}_{2} \mathrm{O}$ oxidation potential modestly by about $20 \mathrm{mV}$ and increased the water oxidation activity by $26 \%$ (from 30.8 to 38.8 $\mu \mathrm{mol} \mathrm{h}{ }^{-1} 100 \mathrm{mg}^{-1}$ in aqueous $\mathrm{AgNO}_{3}$ ). This correlation suggests that the redox rates $R_{\mathrm{OX}}$ and $R_{\mathrm{RED}}$ in eq 1 are substantially smaller than the generation rate $R_{\mathrm{G}}=1.11 \times$ $10^{-4} \mathrm{~mol} \mathrm{~s}^{-1} \mathrm{~cm}^{-3}$. However, absolute values for $R_{\mathrm{OX}} / R_{\mathrm{RED}}$ cannot be established unless the electrochemical potentials of the electrons and holes (the quasi Fermi levels) in the irradiated photocatalysts are known. ${ }^{32-34}$

The rate-limiting water redox kinetics of the niobates also explain the significant increase of $\mathrm{H}_{2}$ evolution rates observed with the addition of methanol (Figure 6 and Table 1). With a thermodynamic oxidation potential of $+0.03 \mathrm{~V}$ (NHE), methanol is much easier to oxidize than water. ${ }^{35}$ As expected, for the nanoniobate, the effect of methanol on $\mathrm{H}_{2}$ evolution is stronger (>300 times rate increase) than for the bulk niobate $(\sim 100$ times) because of the lesser charge transfer limitation (the term $J_{\mathrm{T}}{ }^{+-} / r$ in eq 1 is larger). The same reasoning applies to $\mathrm{O}_{2}$ evolution from aqueous silver nitrate, except that in this case water oxidation without $\mathrm{AgNO}_{3}$ is too slow to be observed at all (Figure 7). Again, with $\mathrm{AgNO}_{3}$ present, the nanoniobate is about four times more active than the bulk niobate because of the lesser charge transport limitation.

The kinetic model also permits mass transport from the liquid bulk phase to the interface to become a rate-limiting factor, especially in the regime of fast catalyst turnover. Essentially, the mass transport limitation on the solution side is analogous to the charge transport limitation in the bulk phase. However, as a comparison of the conversion rates for the most active catalyst (Pt-modified nanoniobate in aqueous methanol) with the diffusion rate of methanol in water reveals (Supporting Information), ${ }^{36}$ the rate of methanol diffusion is by a factor $26 \times 10^{6}$ larger than the turnover rate at the catalyst surface. This shows that diffusion of the sacrificial agent does not play a role under these conditions.

\section{CONCLUSION}

In conclusion, we have compared the photocatalytic water reduction and oxidation performance of nano- and microparticles of a layered niobate. We find that under all conditions (with and without cocatalysts and sacrificial agents) the nanoscale particles are more active than the microscale particles. These results can be rationalized with a kinetic model derived from the one-dimensional continuity equation for illuminated semiconductors. The model shows that the higher activity of the nanoniobate is due to shortened transport paths for electrons and holes to the reactive surface, which reduce lattice recombination. This effect outweighs the increase in surface recombination that is to be expected for the nanomaterial, due to its increased specific surface area. The photocatalytic activities of the nano- and bulk niobate are furthermore limited by slow rates for the water redox reactions, which explains the beneficial effects of the cocatalysts and of the sacrificial agents. The cocatalyst (Pt, IrOx) particle size affects the rate for the nanoniobate but not that of the bulk material. Even at the highest measured turnover rate, the catalytic activity of these suspended photocatalysts is not limited by mass transport of the sacrificial agents or water molecules. That appears to be a distinct advantage of dispersed catalysts over film photoelectrodes.

\section{ASSOCIATED CONTENT}

\section{Supporting Information}

Details for the calculations and additional information on factorial analysis. Electron micrographs of catalysts, timedependent $\mathrm{H}_{2}$ evolution plots of the catalysts in water, and a Beer's law plot. This material is available free of charge via the Internet at http://pubs.acs.org.

\section{AUTHOR INFORMATION}

\section{Corresponding Author}

*E-mail: fosterloh@ucdavis.edu.

\section{ACKNOWLEDGMENTS}

FEO thanks Research Corporation for Science Advancement for a Scialog award. This work was also supported by the National Science Foundation under Grant No. 0829142. NDB thanks the US Department of Energy for support under Grant FG0203ER46057.

\section{REFERENCES}

(1) Kamat, P. V. J. Phys. Chem. C 2007, 111, 2834.

(2) Lewis, N. S. Science 2007, 315, 798.

(3) Lewis, N. S.; Nocera, D. G. Proc. Natl. Acad. Sci. U.S.A. 2007, 104, 20142.

(4) Hoffmann, M. R.; Martin, S. T.; Choi, W. Y.; Bahnemann, D. W. Chem. Rev. 1995, 95, 69.

(5) Kudo, A.; Miseki, Y. Chem. Soc. Rev. 2009, 38, 253.

(6) Domen, K.; Kudo, A.; Shinozaki, A.; Tanaka, A.; Maruya, K.; Onishi, T. J. Chem. Soc., Chem. Commun. 1986, 356.

(7) Fang, M. M.; Kim, C. H.; Saupe, G. B.; Kim, H. N.; Waraksa, C. C.; Miwa, T.; Fujishima, A.; Mallouk, T. E. Chem. Mater. 1999, 11, 1526.

(8) Kato, H.; Asakura, K.; Kudo, A. J. Am. Chem. Soc. 2003, 125, 3082.

(9) Kay, A.; Cesar, I.; Gratzel, M. J. Am. Chem. Soc. 2006, 128, 15714.

(10) Osterloh, F. E. Chem. Mater. 2008, 20, 35.

(11) Sarahan, M. C.; Carroll, E. C.; Allen, M.; Larsen, D. S.; Browning, N. D.; Osterloh, F. E. J. Solid State Chem. 2008, 181, 1678.

(12) Spray, R. L.; McDonald, K. J.; Choi, K.-S. J. Phys. Chem. C 2011, $115,3497$.

(13) Townsend, T. K.; Sabio, E. M.; Browning, N. D.; Osterloh, F. E. ChemSusChem 2011, 4, 185.

(14) Frame, F. A.; Townsend, T. K.; Chamousis, R. L.; Sabio, E. M.; Dittrich, T.; Browning, N. D.; Osterloh, F. E. J. Am. Chem. Soc. 2011, 133, 7264. 
(15) Jacobsen, A. J.; Johnson, J. W.; Lewandowski, J. T. Inorg. Chem. 1985, 24, 3727.

(16) Dion, M.; Ganne, M.; Tournoux, M. Mater. Res. Bull. 1981, 16, 1429.

(17) Fukuoka, H.; Isami, T.; Yamanaka, S. J. Solid State Chem. 2000, $151,40$.

(18) Compton, O. C.; Carroll, E. C.; Kim, J. Y.; Larsen, D. S.; Osterloh, F. E. J. Phys. Chem. C 2007, 111, 14589.

(19) Compton, O. C.; Osterloh, F. E. J. Phys. Chem. C 2009, 113, 479.

(20) Compton, O. C.; Mullet, C. H.; Chiang, S.; Osterloh, F. E. J. Phys. Chem. C 2008, 112, 6202.

(21) Sabio, E. M.; Chi, M.; Browning, N. D.; Osterloh, F. E. Langmuir 2010, 26, 7254.

(22) Ebina, Y.; Sasaki, T.; Harada, M.; Watanabe, M. Chem. Mater. 2002, 14, 4390.

(23) Iwase, A.; Kato, H.; Kudo, A. Chem. Lett. 2005, 34, 946.

(24) Seki, S.; Sekizawa, T.; Haga, K.; Sato, T.; Takeda, M.; Seki, Y.; Sawada, Y.; Yubuta, K.; Shishido, T. J. Vac. Sci. Technol. B. 2010, 28, 188.

(25) Dobosz, A.; Sobczynski, A. Water Res. 2003, 37, 1489.

(26) Laser, D.; Bard, A. J. J. Electrochem. Soc. 1976, 123, 1837.

(27) Jaegermann, W.; Tributsch, H. Prog. Surf. Sci 1988, 29, 1.

(28) Morrison, S. R. Electrochemistry at semiconductor and oxidized metal electrodes; Plenum Press: New York, 1980.

(29) Pleskov, Y. Y.; Gurevich, Y. V. Semiconductor photoelectrochemistry; Consultants Bureau: New York, 1986.

(30) Salvador, P. J. Phys. Chem. B 2001, 105, 6128.

(31) Lewis, N. S. Inorg. Chem. 2005, 44, 6900.

(32) Shockley, W. Bell Syst. Tech. J. 1949, 28, 435.

(33) Tan, M. X.; Kenyon, C. N.; Lewis, N. S. J. Phys. Chem. 1994, 98, 4959.

(34) Gerischer, H. Electrochim. Acta 1990, 35, 1677.

(35) Burstein, G. T.; Barnett, C. J.; Kucernak, A. R.; Williams, K. R. Catal. Today 1997, 38, 425.

(36) Derlacki, Z. J.; Easteal, A. J.; Edge, A. V. J.; Woolf, L. A.; Roksandic, Z. J. Phys. Chem. 1985, 89, 5318. 